\title{
The Influence of Job Autonomy on Job Satisfaction in Thai Fitness Trainer Professionals: A Moderation Analysis
}

\section{Terason $\mathbf{S}^{*}$}

Faculty of Sports Science, Kasetsart University, Thailand

\begin{abstract}
Job autonomy and job satisfaction have been the foci of organizational research for the past few decades; yet, only a few studies have been conducted in fitness industry context. This study attempts to examine how job autonomy of the fitness trainer professionals working in fitness facilities was related to job satisfaction and how the relationship of the two variables was moderated by managerial responsibility. Building on the research surrounding job autonomy and job satisfaction, the author proposed a model in which the managerial function of these individuals moderated the impact of job autonomy on job satisfaction. Data were collected from those professionals at randomly chosen fitness establishments around Thailand. A hierarchical multiple regressions were performed with linear interaction terms. The relationship between job autonomy and job satisfaction was found to depend on whether one was assigned managerial responsibility. The implications for future research and policy were also provided to fitness establishments in the country.
\end{abstract}

Keywords: Job autonomy; Job satisfaction; Fitness trainer; Managerial responsibility

\section{Introduction}

A fitness trainer professional is an individual certified to have a varying degree of knowledge of general fitness involved in exercise mechanism, health care, and nutrition consumption [1]. A fitness establishment cannot be dispensed with staff of this genre. Fitness instructors or personal trainers are expected to motivate clients in their exercise routine, to assess clients' fitness strengths and weaknesses, to assess clients' progress in physical exercise, and to educate them about wellness, health and nutrition. Fitness trainers set exercise goals, provide fitness instruction, and customize health regulations for clients. In most fitness facilities, full-time, salaried trainers also assume managerial responsibility on top of the aforementioned duties.

Generally, as in an organization, it is believed that, when fitness professionals are satisfied with work, it contributes to high organizational commitment and low turnover rate [2,3]. Therefore, there have been attempts to enhance the well-being of employees. For this reason, researchers try to find out whether employees are satisfied with their jobs $[4,5]$. There are various compelling reasons why an employer should care about job satisfaction. Job satisfaction is a topical topic of considerable interest to fitness club employers due to the high turnover rate in recent years.

Job satisfaction is generally deemed as a positive emotional state that reflects an effective response to a job situation. Job satisfaction is one of the central variables in organizational research and is also seen as an important indicator of working life quality [6]. Satisfaction and contentment of an individual at work are essential in maintaining overall life balance $[7,8]$.

Job satisfaction displays components that are behavioral, cognitive, and emotional in nature [9]. The behavioral component deals with work related actions and could include questioning the job or status quo. The cognitive component is exemplified by a belief that the job is challenging or demanding, and could include learning and applying new knowledge. The emotional component involves excitement or peer recognition, constitute emotions. Virtually every employee comes to organizations with some expectations and corresponding skill sets and hopes to work in an environment where he can use their abilities and satisfy their needs [10]. The social aspects of a job may increase satisfaction and may also benefit the organization as a whole [11]. Employees find social factors to be more critical than the nature of the job, compensation, and knowledge, in advancing job satisfaction [12]. The social activities and initiatives fall within the domain of management's work role and potentially contribute to job satisfaction.

Job satisfaction has been chosen as a dependent variable for the study because it is one of the most widely studied variables in organizational research [13]. In addition, it has shown to have meaningful relationships to a number of important variables such as performance, organizational citizenship behavior and turnover intentions. Furthermore, there has been a limited amount of research addressing the relationship between autonomy and various outcomes variables, including job satisfaction [14].

One of the factors that are believed to influence job satisfaction is job autonomy [15]. Job autonomy is defined in a variety of ways. It is the degree to which the job offers considerable liberty, providing a free hand to the individual in scheduling the work also defining the means to achieve their tasks [12]. It is also defined as the amount of job-related independence, initiative, and freedom permitted or required in daily work activities. Autonomy involves exercising control over methods used to perform work activities, the scheduling of those activities, and the standards used to judge performance [16].

Breaugh [16] refers to the freedom to make decisions and the discretion to act in the manner an employee best see fit as job autonomy. Autonomy offers the individual an objective sense of control within the domain of task methodology and execution, and accentuates the power of the employee to make his or her own decisions. Having autonomy gives the employees the freedom to make decisions at work,

*Corresponding author: Terason S, Faculty of Sports Science, Kasetsart University, Thailand, Tel: +66 2942 8200; E-mail: sterason@gmail.com

Recieved February 05, 2018; Accepted February 19, 2018; Published February 26, 2018

Citation: Terason S (2018) The Influence of Job autonomy on Job Satisfaction in Thai Fitness Trainer Professionals: A Moderation Analysis. J Entrepren Organiz Manag 7: 225. doi: 10.4172/2169-026X.1000225

Copyright: (c) 2018 Terason S. This is an open-access article distributed unde the terms of the Creative Commons Attribution License, which permits unrestricted use, distribution, and reproduction in any medium, provided the original author and source are credited. 
provides them with the capacity to influence their work schedule, and to determine the procedures used to complete it $[17,18]$.

Research on job autonomy on the other hand has gained the attention of researchers because of the benefits it brings not only to employees but also to organizations [5]. Autonomy is actually one of the job design characteristics [13]. Job autonomy improves performance because when employees are able to exercise a certain level of job autonomy; they consider that they are trusted to perform the task well. Studies have investigated the influence of job autonomy on job satisfaction which was primarily qualitative in nature which were descriptive and employing a small sample [19].

Given that there is evidence suggesting that the positive effects of job autonomy are more evident under high levels of performance feedback, it would be expected that the stress buffering effects of job autonomy would also be more evident at high levels of performance feedback $[18,20]$. A logical extension of this line of reasoning is that autonomy would be expected to provide more advantage in coping with job demanding situations and, in turn, to enhance employee attitudes if one had useful performance feedback. That is, in a high performance feedback condition, having a high level of job autonomy moderates the relationship between role ambiguity and employee satisfaction.

Job autonomy is linked to greater degrees of decision latitude, job satisfaction, and better work performance [17]. Autonomy may be viewed as the employees' perception of the amount of control they possess over work-related behaviors. From a humanistic view, it is assumed that satisfaction with job is a basic value that should be attainable for all fitness trainer professionals, and that the provision of avenues for job autonomy in the workplace may result in job satisfaction among workers [21].

Job autonomy enhances employees' feelings that job outcomes are a result of their efforts [22]. Actually, very few studies have examined the impact of job autonomy on job satisfaction [15]. Research in the field of organizational behavior suggests a positive relationship between job autonomy and job satisfaction-it is believed that more autonomy is expected to be associated with greater job satisfaction. In other words, high levels of work autonomy may lead to high levels of job satisfaction $[5,18]$. This is due to that fact that employees have more freedom to determine their own effort and work schedule especially among sport professionals in sport or coaching environment. Therefore, it is hypothesized as follows:

H1: The level of job autonomy a fitness trainer professional is allowed predicts the level of satisfaction they feel with their job.

In the current study, managerial responsibility encompasses controlling, directing, organizing, planning and staffing functions of fitness professional. The controlling function involves setting strategic and tactical goals, monitoring the performance of fitness trainers against these goals, and taking corrective action when performance does not match expectations. In the directing role, managers communicate goals, motivate subordinates to get these goals, and provide comments. The organizing function concerns setting schedules and budgets, assigning authority, and coordinating research and development activities. The planning function relates to strategic activities, such as formulating long-term plans, looking for buy-off opportunities and planning expansions. The staffing function refers to human resource functions, such as recruiting, selecting, hiring and training new staff. In a fitness establishment, a fitness trainer could be assigned managerial responsibility which could either mitigate or increase their job satisfaction [23-25]. Thus, it is hypothesized as follows:
H2: In fitness facilities, the relationship between job autonomy and job satisfaction is moderated by whether a fitness trainer professional is assigned managerial responsibility.

\section{Method}

\section{Participants}

The target population of the study was represented by fitness trainer professionals who were hired as full-time employees by fitness facilities around Thailand. Based on an approximate population size of 20,000 and a margin of error of $5 \%$ as well as a $95 \%$ confidence level, the required sample size was 370 . The projected response rate was $80 \%$; consequently, 463 fitness trainers were either directly or indirectly contacted. However, only 372 people consented to participating.

The multistage sampling plan was executed. As such, the target population of fitness facilities was divided into five clusters according to the geographic regions. Then, three out of five clusters were randomly chosen; next, the portion of facilities in each region was selected at random. Finally, every fitness trainer within the chosen facilities was randomly sampled from the rosters.

The demographic characteristics of the respondents are shown in Table 1. The final sample was composed of slightly more females (52\%) than males (48\%). Most of the participants (35\%) were between 21 and 30 years of age. Most of them were single (53\%). Almost all of the respondents (95\%) held a university degree. Besides, most of them (39\%) had worked at their current establishments for fewer than 5 years.

\section{Measures}

The questionnaire was developed on the basis of a literature review on previous research studies on job autonomy and job satisfaction. Adaptations were made to the scales such that they are appropriate for the human resource in sport and exercise context. The scales were rend from English into Thai, and then back-translated with the aim of

\begin{tabular}{|l|c|c|}
\hline Characteristic & $\boldsymbol{n}$ & $\%$ \\
\hline Gender & 178 & 48 \\
\hline Male & 194 & 52 \\
\hline Female & & 18 \\
\hline Age & 68 & 35 \\
\hline$<20$ & 129 & 33 \\
\hline $21-30$ & 122 & 14 \\
\hline $31-40$ & 53 & 53 \\
\hline $41+$ & 199 & 42 \\
\hline Marital status & 156 & 5 \\
\hline single & 17 & 5 \\
\hline married & & 95 \\
\hline divorced & 20 & 39 \\
\hline Education level & 352 & 32 \\
\hline high school & 137 & 20 \\
\hline university & 122 & 9 \\
\hline Tenure & 73 & 39 \\
\hline$<5$ & 33 & \\
\hline $5-10$ & & 372 \\
\hline $11-15$ & & \\
\hline $15>$ & & \\
\hline Managerial responsibility & & \\
\hline Managerial & & \\
\hline Non managerial & & \\
\hline & & \\
\hline
\end{tabular}

Table 1: Demographic Characteristics of Participants $(\mathrm{N}=372)$. 
validating language accuracy. Furthermore, the contents of the scales were assessed for validity by three reviewers. The job autonomy scale was adapted from the Work Autonomy scale [16]. It consists of eight questions assessing work autonomy, method autonomy, scheduling autonomy, and criteria autonomy as delineated in Table 2 . The scale was measured on a 5-point summated rating scale; participants were asked to rate each item on the scale from 1 (strongly disagree) to 5 (strongly agree). The higher a score an employee rated, the more autonomous he or she felt at work. The Cronbach's alpha was .78, reflecting satisfactory statistical reliability.

The job satisfaction scale was adapted from those used in prior research $[9,26]$. It consists of six questions assessing the cognitive, emotional, and behavioral components associated with an individual's feelings, beliefs, mental and intellectual challenges, and actions. Table 2 shows the complete set of the items. Responses to these questions scored between 1 (strongly disagree) and 5 (strongly agree). A highest score of 30 indicates respondents' highest level of satisfaction with their job whereas a lowest score of 6 reveals they were least satisfied with their employment. The Cronbach's alpha for the job satisfaction scale was .71, indicating that the scale had reasonable internal consistency reliability.

The respondents were additionally inquired about their gender (male vs. female), age, marital status (single, married, or divorced), education (high school vs. college), years of tenure, and managerial responsibility (managerial vs. non managerial). However, only managerial responsibility was put into the moderation analysis while the rest were treated as control variables.

\section{Analysis}

To test the hypothesis, hierarchical regression analyses were conducted, with job satisfaction is used as an independent variable whereas job autonomy was used a dependent variable, in order to assess the statistical significance of the interaction term between job autonomy and managerial responsibility. A moderation analysis is used to determine whether the relationship between job autonomy and job satisfaction depends on, or is moderated by, the value of managerial responsibility. This type of analysis referred to as a moderated multiple regressions or MMR [27] involves the addition of a Job Autonomy $\times$ Managerial interaction term in one model and a Job Autonomy $\times$ Non managerial term in another model.

\section{Procedure}

Initially, 463 fitness trainers selected were contacted, but 372 of them responded and consented to participating in the survey with no pay. Then, these individuals were briefed on the purpose and scope of the study. To proceed with data collection, they were requested to evaluate job autonomy they were given in their workplace and job satisfaction they gained when working there. The data gathered were either in papers or in electronic form.

\section{Results}

A scatterplot of job satisfaction against job autonomy was plotted. Visual inspection of this plot indicated that the assumption of linearity was met. Besides, no evidence of multicollinearity was detected, as evidenced by no tolerance values less than 0.138 . In spite of a few outliers, leverage points, or influential cases detected, none seemed to need elimination. Homoscedasticity was ascertained, as assessed by visual inspection of the studentized residuals plotted against the predicted values for managerial and non-managerial fitness trainers. The studentized residuals were normally distributed, as assessed by Shapiro-Wilk's test $(\mathrm{p}=.077)$.

A hierarchical multiple regressions were run to assess the increase in variation explained by the addition of an interaction term between job autonomy level and job satisfaction to a main effects model. There was a statistically significant moderator effect of managerial responsibility, as supported by the addition of the interaction term explaining a statistically significant increase in total variation explained by $6.8 \%$, $\mathrm{F}(1,368)=0.199, \mathrm{p}=.021$. The difference in slope coefficients between these two simple regressions was not equal to zero in the population. The coefficient of the interaction term was statistically significant, $\mathrm{b}=1.08, \mathrm{SE}=1.01, \mathrm{p}<.001$ ) indicating that managerial responsibility moderated the relationship between job autonomy and job satisfaction. For a physical activity level of 4 , the difference between job satisfaction for managerial fitness trainers $(\mathrm{M}=4.11, \mathrm{SE}=1.47)$ and non-managerial fitness trainers $(\mathrm{M}=3.03, \mathrm{SE}=1.46)$ is $1.80,95 \% \mathrm{CI}[0.68,3.18], \mathrm{p}<.001$. A simple slopes analysis revealed that there was a statistically significant positive linear relationship between job autonomy and job satisfaction amount in managerial fitness trainers, $b=0.13, S E=0.219, p=.041$, but not in non-managerial ones, $\mathrm{b}=0.03, \mathrm{SE}=0.013, \mathrm{p}=.433$.

\section{Discussion}

The primary purpose of the present research was to explore

\begin{tabular}{|l|l|}
\hline Variable & Example questionnaire items \\
\hline Job autonomy & I have significant autonomy in determining how I do my fitness job. \\
\hline & I can decide on my own how to go about serving the needs of the Fitness clients. \\
\hline I have considerable opportunity for independence and freedom in how I do my job. \\
\hline I design important aspects of my own work and put my ideas into practice. \\
\hline I can decide when to come to work and leave work, either officially or unofficially. \\
\hline $\begin{array}{ll}\text { I can take a day off from work without losing pay or having to claim vacation time, sick leave, or put in compensatory time on my } \\
\text { job, either officially or unofficially. }\end{array}$ \\
\hline I can considerably slow down my pace of work for a day when I want to. \\
\hline I can decide on my own to approach or choose a new fitness client that I would like to serve. \\
\hline Job satisfaction & Generally speaking, I am very satisfied with the job at this fitness club. \\
\hline & I am generally satisfied with the kind of job position I do here. \\
\hline Most people in this job are very satisfied with the fitness job. \\
\hline How satisfied are you with the amount of pay that you receive? \\
\hline How satisfied are you with the number of opportunities for promotion at this fitness club? \\
\hline How satisfied are you with the quality of direct supervision you receive? \\
\hline
\end{tabular}

Table 2: Example Questionnaire Items for the Two Variables. 
the relationship between job autonomy and job satisfaction as it was moderated by managerial responsibility among fitness trainer professionals. The hypothesis posited a positive and significant relationship between job autonomy and job satisfaction. This relationship indicated that the greater the job autonomy in the workplace, the more the fitness trainer professionals feel satisfied with their work. The current findings supported the first hypothesis that job autonomy affected job satisfaction. Nevertheless, this did not hold true for all of the fitness trainer professionals-on one hand, those employees who were assigned managerial responsibility tended to be satisfied with their work when they were allowed autonomy. On the other hand, for those without such responsibility, the degree of satisfaction was not dependent on job autonomy. The second hypothesis was therefore supported.

Overall, the findings were consistent with prior research $[4,5,28]$. Most of those studies advocated the degree of job satisfaction is highly and statistically related to the amount of job satisfaction. It is interesting to speculate on possible reasons why job autonomy affected job satisfaction in managerial fitness professionals. One possibility is that employees feel empowered due to the degree of autonomy and self-determination [19]. As such, they have the proclivity to be content with their work, given the amount of power they can exercise in the workplace. As a result, fitness trainer professionals should be given the authority to make decisions about the services they render and any top-down imposition of change is counter to the development of professionalism [14]. In a nutshell, the findings demonstrate that the greater the propensity for job autonomy, the greater the propensity for fitness trainer professionals to be satisfied with their job.

Fitness trainer professionals should be granted autonomy to make decisions about their work through managerial duties. Employees with autonomy have the liberty to control the pace of work and to regulate work processes and evaluation procedures which may result in using skillful and creative initiatives in accomplishing their tasks and performing the job better [20]. Previous researchers also found positive association between job autonomy and job satisfaction $[28,29]$.

Limitations of this study provide opportunities for future research on job autonomy and job satisfaction. First, the sample was limited to fitness enterprises in Thailand and does not include those in the government-owned facilities which are characterized by bureaucracy and the hierarchical structure. Future studies could thus draw comparisons between the two. Second, several other factors affecting employee job satisfaction was not included in the inquiry. A future study could take into consideration other associated variables such as organizational commitment, turnover intention, absenteeism, and performance; these antecedents impact a worker's efficiency and an organization's productivity.

Another interesting avenue for future research is to apply a qualitative approach to the investigation as done in prior studies [19]. Replication of this study is therefore warranted because this research has been exploratory in nature. Finally, development of new, robust scales for each construct through conceptualization and operationalization will be helpful in better understanding these constructs and the relationship between job satisfaction and its prospective antecedents applicable to fitness trainer professionals [30]. Despite these limitations, the research findings support the descriptive literature on the possible relationships among the constructs used in the study, namely job autonomy and job satisfaction.

\section{References}

1. Fischer DV, Bryant $\mathrm{J}$ (2008) Effect of certified personal trainer services on stage of exercise behavior and exercise mediators in female college students. Journal of American College Health 56: 369-376.

2. Ying LH, Ahmad KZB (2009) The moderating effects of organizational culture on the relationship between leadership behavior and organizational commitmen and between organizational commitment and job satisfaction and performance. Leadership \& Organization Development Journal 30: 53-86

3. Yousef DA (2017) Organizational commitment, job satisfaction and attitudes toward organizational change: A study in the local government. International Journal of Public Administration 40: 77-88.

4. Llorente RMB, Macias EF (2005) Job satisfaction as an indicator of the quality of work. Journal of Socio-Economics 34: 656-673.

5. Naqvi SMMR, Ishtiaq M, Kanwal N, Ali M (2013) Impact on job autonomy on organizational commitment and job satisfaction: The moderating role of organizational culture in the fast food sector of Pakistan. International Journal of Business and Management 8: 92-102.

6. Aryee S, Fields D, Luk V (1999) A cross-cultural test of model of the work-family interface. Journal of Management 25: 491-511.

7. Jin MH, Guy ME (2009) How emotional labor influences worker pride, job satisfaction, and burnout. Public Performance \& Management Review 33: 88105

8. Sadri S, Goveas C (2013) Sustainable quality of work life and job satisfaction (An Indian Case). Elite Research Journal of Education and Review 1: 48-54.

9. Bernstein DA (2018) Essentials of psychology. Boston, MA: Cengage.

10. Turker D (2009) How corporate social responsibility influences organizational commitment. Journal of Business Ethics 89: 189.

11. Williams JJ, Seaman AE (2018) Job satisfaction: Are corporate social responsibility initiatives beneficial and do different governance structures matter? Journal of Applied Business Research 34: 23-41.

12. Morgeson FP, Delaney-Klinger K, Hemingway MA (2005) The importance of job autonomy, cognitive ability, and job-related skill for predicting role breadth and job performance. Journal of Applied Psychology 90: 399-406.

13. Cranny CJ, Smith PC, Stone EF (1998) Job satisfaction: How people feel about their jobs and how it affects their performance. New York, NY: Lexington Books.

14. Dhurup M (2015) Modeling The Effects Of Social Integration And Job Autonomy On Job Satisfaction Among School Sport Facilitators In Southern Gauteng Journal of Applied Business Research 31: 275-284.

15. Rodríguez D, Buyens D, Landeghem HV, Lasio V (2016) Impact of lean production on perceived job autonomy and job satisfaction: An experimental study. Human Factors \& Ergonomics in Manufacturing \& Service Industries 26: 159-176.

16. Breaugh JA (1999) Further investigation of the work autonomy scales: Two studies. Journal of Business and Psychology 13: 357-373.

17. Chua RYJ, lyengar SS (2011) Perceiving freedom givers: Effects of granting decision latitude on personality and leadership perceptions. Leadership Quarterly 22: 863-880

18. Yang L, Emerson DJ, Brink AG (2016) Job autonomy and counterproductive behaviors in Chinese accountants: The role of job-related attitudes. Journal of International Accounting Research 15: 115-131.

19. Min KR, Ugaddan RG, Park SM (2017) Is the creative tendency affected by organizational leadership and employee empowerment? An empirical analysis of U.S. federal employees. Public Performance \& Management Review 40 : 382-408.

20. Saragih S (2011) The effects of job autonomy on work outcomes: Self-efficacy as an intervening variable. International Research Journal of Business Studies 4: 203-215.

21. Kim H, Stoner M (2008) Burnout and turnover intention among social workers: Effects of role stress, job autonomy and social support. Administration in Social Work 32: 5-25.

22. Wang G, Netemeyer RG (2002) The effects of job autonomy, custome demandingness, and trait competitiveness on salesperson learning and selfefficacy, and Performance. Journal of Academy of Marketing Science 30: 217 228.

23. Baïada-Hirèche L, Pasquero J, Chanlat JF (2011) Managerial responsibility as 
Citation: Terason S (2018) The Influence of Job autonomy on Job Satisfaction in Thai Fitness Trainer Professionals: A Moderation Analysis. J Entrepren Organiz Manag 7: 225. doi: 10.4172/2169-026X.1000225

Page 5 of 5

negotiated order: A social construction perspective. Journal of Business Ethics 101: 17-31.

24. Fransen L, Burgoon B (2014) Privatizing or socializing corporate responsibility: Business participation in voluntary programs. Business \& Society 53: 583-619.

25. Pérezts M, Bouilloud JP, Gaulejac VD (2011) Serving two masters: The contradictory organization as an ethical challenge for managerial responsibility. Journal of Business Ethics 101: 33-44.

26. Nagy MS (2002) Using a single-item approach to measure facet job satisfaction. Journal of Occupational and Organizational Psychology 75: 77-86.
27. Aguinis $H$ (2004) Methodology in the social sciences. Regression analysis for categorical moderators. New York, NY: Guilford Press.

28. Finn CP (2001) Autonomy: An important component for nurses' job satisfaction International Journal of Nursing Studies 38: 349-357.

29. Thompson CA, Prottas DJ (2005) Relationship among organisational family support, job autonomy, perceived control and employee well-being. Journal of Occupational Health Psychology 11: 100-118.

30. Yang TS, Pandey A, Liao YC, Dobson JJ (2017) A path from job autonomy to organizational citizenship behavior: The role of perceived organizational politics as mediator. Journal of Business and Behavioral Sciences 29: 44-56. 